\title{
Diagnosis of Medium-Chain Acyl-CoA Dehydrogenase Deficiency in Lymphocytes and Liver by a Gas Chromatographic Method: The Effect of Oral Riboflavin Supplementation
}

\author{
M. DURAN, C. B. J. M. CleutJens, D. KeTting, L. DORLAND, J. B. C. DE KLERK, \\ F. J. VAN SPRANG, AND R. BERGER \\ University Children's Hospital, "Het Wilhelmina Kinderziekenhuis," Utrecht, The Netherlands [M.D., \\ C.B.J.M.C., D.K., L.D., F.J.v.S., R.B.]; and Sophia Children's Hospital, Erasmus University, Rotterdam, \\ The Netherlands [J.B.C.d.K.]
}

\begin{abstract}
The activity of medium-chain acyl-CoA dehydrogenase (MCAD) with octanoyl-CoA as a substrate was measured in human lymphocytes by a gas chromatographic technique. Phenazine methosulfate was used as the primary electron acceptor. After the addition of crotonase and subsequent hydrolysis, the reaction product 3-hydroxyoctanoic acid was quantitated by capillary gas-liquid chromatography of the trimethylsilyl derivatives. Control subjects had MCAD activities of $3.46 \pm 0.18 \mathrm{nmol} / \mathrm{mg}$ protein/ $\min (n=15)$. Five patients were investigated while receiving no therapy at all; MCAD activity ranged from 0.08 to 0.23 in four of them and was 0.65 in the fifth one. Subsequent to the long-term administration of $50-150 \mathrm{mg} / \mathrm{d}$ of riboflavin to MCAD-deficient patients $(n=11)$, these activities increased to an average of 0.41 in 10 patients and 2.22 in one. The activities in 15 obligate heterozygotes were $1.91 \pm 0.41 \mathrm{nmol} / \mathrm{mg}$ protein $/ \mathrm{min}$, thus enabling a clear distinction from controls. Neither heterozygotes nor a control responded to riboflavin. The method was also applicable to postmortem liver tissue. One patient, who had died suddenly and unexpectedly at the age of $19 \mathrm{mo}$, was correctly diagnosed as MCAD-deficient, whereas five additional children who died of the sudden infant death syndrome showed normal activities. (Pediatr Res 31: 3942, 1992)
\end{abstract}

\section{Abbreviations}

ETF, electron-transferring flavoprotein

FAD, flavin adenine dinucleotide

MCAD, medium-chain acyl-CoA dehydrogenase

PMS, phenazine methosulfate

TMC, trimethylsilyl

Over the past decade, the interest in the study of inherited defects of mitochondrial fatty acid $\beta$-oxidation has grown considerably, in part because some of these defects have been associated with the so-called sudden infant death syndrome (1). Theoretically, every defect of the complicated system of mitochondrial $\beta$-oxidation of long-chain fatty acids will lead to hypoketotic hypoglycemia, often with neurologic complications

Received February 11, 1991; accepted July 22, 1991.

Correspondence and reprint requests: M. Duran, Ph.D., University Children's Hospital, "Het Wilhelmina Kinderziekenhuis," P.O. Box 18009, NL-3501 CA Utrecht, The Netherlands.

Supported by a gift of Chrompack BV, Middleburg, The Netherlands. such as convulsions or coma (2). The clinical consequences of defective fatty acid oxidation occur only episodically. There are enzyme-deficient subjects who never have an attack. Therefore, no exact data about the frequency of the fatty acid oxidation disorders are available, but there appears to be general agreement that the deficiency of MCAD is probably the most frequent defect (3). From the number of carriers in the general population, the incidence of homozygotes can be estimated to be at least 1:18.500 in Western European countries (4), a figure similar to that observed for phenylketonuria.

Various laboratory methods based on the chromatographic separation and mass spectrometric identification of characteristic metabolites in plasma and urine are available as a first diagnostic approach. Because of the intermittent character of both the clinical and the biochemical abnormalities, this approach may not be entirely satisfactory in all cases. As a consequence, there is a need for a reliable enzyme assay that can also be used for genetic studies. In general, the enzymatic diagnosis of MCAD deficiency can be achieved by several different methods, such as the fluorometric ETF-reduction assay (5) and the radiochemical whole fibroblast oxidation method, making use of the ${ }^{14} \mathrm{CO}_{2}$ production rate from ${ }^{14} \mathrm{C}$-octanoate (6). The former method has the disadvantage that purified ETF, which is not commercially available, is indispensable for the assay, whereas the latter technique may suffer from rather high blank values and a poor reproducibility.

Moreover, the octanoate degradation test in whole fibroblasts does not discriminate between heterozygotes and healthy controls, which is disadvantageous when genetic advice is sought. Several years ago Kolvraa et al. (7) proposed another approach for fibroblasts, making use of stable isotope-labeled substrates and mass selective detection of the isotopically labeled product. Here we present a simple gas chromatographic technique. Octanoyl-CoA is converted by endogenous MCAD to octenoyl-CoA, which in turn is hydrated by exogenous crotonase. The final reaction product, 3-hydroxy-octanoyl-CoA, is converted by alkaline hydrolysis into 3-hydroxyoctanoate and quantitated as such.

\section{MATERIALS AND METHODS}

Medium-chain CoA esters were obtained from Sigma Chemical Co., St. Louis, MO, as were the electron acceptor PMS, crotonase, and L-carnitine. Tromboliquine (heparin) was a product of Organon Teknika, Boxtel, The Netherlands. Ficoll-Paque was from Pharmacia (Piscataway, NJ), FAD was from Boehringer Mannheim (Indianapolis, IN) and L-cysteine was from Fluka AG, Buchs, Switzerland. 3-Hydroxyoctanoic acid was synthe- 
sized by a Reformatzky reaction from hexanal and ethylbromoacetate in the presence of zinc powder (8). Its mass spectrum (TMS derivative) showed the expected (M-15) mass at $\mathrm{m} / \mathrm{z}=$ 289 and a prominent fragment at $\mathrm{m} / \mathrm{z}=173$ (M-COOTMS$\mathrm{CH}_{2}$ ). All other chemicals were of the highest purity available.

Mononuclear leukocytes were isolated from $10-20 \mathrm{~mL}$ freshly drawn blood, which was heparinized with $0.5 \mathrm{~mL}$ Tromboliquine (1:20 in PBS) in the recipient vessel. The blood was diluted 1:1 with PBS, and the cells were separated by the Ficoll-Paque method. After the cells were washed with PBS, they were stored as a pellet at $-80^{\circ} \mathrm{C}\left(\sim 4 \times 10^{6}\right.$ cells/vial $)$ until analysis.

The enzyme reaction was allowed to proceed in the dark. A cell pellet was sonicated on ice by three 10-s bursts of the microtip and subsequently dissolved in $1 \mathrm{~mL}$ of a $0.75 \mathrm{M} \mathrm{K}_{2} \mathrm{HPO}_{4}$ buffer, $\mathrm{pH}$ 7.5. Usually, $0.3 \mathrm{~mL}$ of this solution was taken. The reaction mixture, prepared in the dark in aluminum-wrapped glass-stoppered test tubes, totaled $0.8 \mathrm{~mL}$ and had the following composition: $0.10 \mathrm{mM}$ FAD; $0.36 \mathrm{mM}$ cysteine; $5.02 \mathrm{mM}$ PMS; 0.25 $\mathrm{mM}$ octanoyl-CoA; and $0.75 \mathrm{U}$ crotonase. Incubation was done at $37^{\circ} \mathrm{C}$ for $30 \mathrm{~min}$, after which the reaction was stopped by adding $0.5 \mathrm{~mL} 0.1 \mathrm{M} \mathrm{NaOH}$.

The $\mathrm{COA}$ esters in the reaction mixture were hydrolyzed by heating the alkaline solution at $60^{\circ} \mathrm{C}$ for $30 \mathrm{~min}$. Before extraction of the liberated organic acids, the internal standard $(0.4 \mathrm{mg}$ 3 -phenylbutyric acid) was added and $1.2 \mathrm{~mL}$ of a saturated $\mathrm{NaCl}$ solution and 12 drops of $2 \mathrm{M} \mathrm{HCl}$ were also added. Extraction was done twice with $2.5 \mathrm{~mL}$ of diethyl ether. The combined organic layers were dried over anhydrous $\mathrm{Na}_{2} \mathrm{SO}_{4}$ and evaporated to dryness with the use of a rotary evaporator at room temperature. Trimethylsilylation of the organic acids was performed in glass-stoppered tubes with $100 \mathrm{~mL}$ of N,N-bis(TMS)trifluoroacetamide/pyridine/trimethylchlorosilane $(5: 1: 0.05 \mathrm{vol} / \mathrm{vol})$ at $60^{\circ} \mathrm{C}$ for $30 \mathrm{~min}$.

Organic acids were separated by capillary gas-liquid chromatography on a $25 \mathrm{~m} \times 0.25 \mathrm{~mm}$ CPSil 19CB column (film thickness $0.19 \mathrm{~mm}$ ) that was fitted into a CP9000 gas chromatograph. Both items were supplied by Chrompack BV, Middelburg, The Netherlands. Nitrogen was used as carrier gas at an inlet pressure of $85 \mathrm{kPa}$ and a gas flow rate of $1.3 \mathrm{~mL} / \mathrm{min}$; the split ratio was $1: 18$. The column temperature was initially maintained at $60^{\circ} \mathrm{C}$ for $5 \mathrm{~min}$, followed by a $5^{\circ} \mathrm{C} / \mathrm{min}$ increase to $270^{\circ} \mathrm{C}$. One $\mu \mathrm{L}$ was injected, and the flame ionization detector was set at such a sensitivity that 2 pmol of 3-OH-octanoate could easily be detected. In selected cases, the identity of the reaction product was verified by gas chromatography/mass spectrometry using a Ribermag R10-10 C quadrupole instrument.

For the investigation of human liver, approximately $20 \mathrm{mg}$ of tissue, which had been stored at $-80^{\circ} \mathrm{C}$, was dissolved in $1 \mathrm{~mL}$ $0.75 \mathrm{M} \mathrm{K}_{2} \mathrm{HPO}_{4}$. The tissue was first homogenized in a Potter homogenator and, subsequently, the cells were disrupted by sonication. Solid remnants were removed by centrifugation at $40000 \times g$ for $40 \mathrm{~min}$. The protein concentration of the supernatant was adjusted to values of $0.06-0.3 \mathrm{mg} / \mathrm{mL}$. Protein was determined by the classic Lowry method (9).

Subjects. Eleven patients with a deficiency of MCAD were included in this study. MCAD deficiency was suspected because of the characteristic profile of urinary and plasma organic acids, including suberylglycine, hexanoylglycine, and the $\mathrm{C}_{6}-\mathrm{C}_{10}$ dicarboxylic acids. Diagnosis was confirmed in the majority of the patients by the finding of a decreased ${ }^{14} \mathrm{C}$-octanoate oxidation in cultured whole fibroblasts $(10,11)$. Six patients gave positive results when subjected to an oral phenylpropionic acid loading test (12).

Five patients were tested before and after a 3 -wk trial of pharmacologic doses of riboflavin $(50-150 \mathrm{mg} / \mathrm{d})$; the remaining six were already on vitamin supplementation for many months.

In addition, we tested 15 obligate heterozygotes (parents of the affected patients), as well as 15 healthy adults recruited from the laboratory staff and students. All tested subjects gave their informed consent. Two obligate heterozygotes and one control subject underwent the same riboflavin supplementation regimen as the patients. None of the subjects who were given riboflavin experienced adverse effects.

Liver tissue was obtained post-mortem from five children who had died without evidence of a fatty acid oxidation defect and one child who died suddenly at the age of 19 mo from MCAD deficiency. In addition, we analyzed a biopsy sample from one surviving patient with the same defect. The time of storage of the tissue samples varied from a few weeks to $8 \mathrm{y}$.

\section{RESULTS}

An enzyme assay making use of chromatographic product analysis relies on its quantitative measurement. To verify this, we demonstrated that the gas chromatographic retention times of 3-OH-octanoic acid and 3-phenylbutyric acid using the current instrumentation and temperature program differed by approximately $15 \mathrm{~s}$, enabling a greater than $90 \%$ separation. The detector response was tested with various concentrations of 3-OH-octanoic acid. A linear relationship was observed for injected amounts varying from 1.5 to 30 pmol. Mass spectrometric identification of 3-OH-octanoic acid was achieved by comparison with the spectrum of the reference compound. Its fragmentation pattern was rather specific, indicating cleavage of the silylated molecule in positions adjacent to the 3-hydroxy group $(\mathrm{m} / \mathrm{z}=131 ; 173 ; 233)$.

All manipulations involving the use of FAD, which is moderately light-sensitive, and the highly sensitive PMS were carried out in the dark. Omission of this precaution leads to apparent 10 -fold lower activities. Preparation of the reaction mixture was done in a dark room with only a photographic red lamp.

The present MCAD assay was linear with time up to $40 \mathrm{~min}$ and with protein ( 0.01 to $0.16 \mathrm{mg} /$ assay). Preferably, an amount of protein between 0.05 and $0.10 \mathrm{mg}$ was chosen for testing cells from patients. Lymphocyte MCAD attained a maximum activity at two different $\mathrm{pH}$ values, viz. 7.5 and 8.1, the latter yielding an only fractionally higher activity (Fig. 1). All further experiments using cells from patients and heterozygotes were performed at $\mathrm{pH} 7.5$.

Maximum velocity of the enzyme reaction was dependent on the concentration of octanoyl-CoA in the mixture. No further increase of the velocity was noticed when these concentrations exceeded $0.16 \mathrm{mM}$. Therefore, a safe concentration of $0.25 \mathrm{mM}$ of octanoyl-CoA was taken in further experiments.

PMS suffers not only from its sensitivity to light, but also from its poor solubility in the phosphate buffer. We tested the effect of varying the PMS concentration on the velocity of the reaction and found that no further increase took place at PMS values greater than $5.02 \mathrm{mM}$. Therefore, the latter value was chosen as the ultimate concentration.

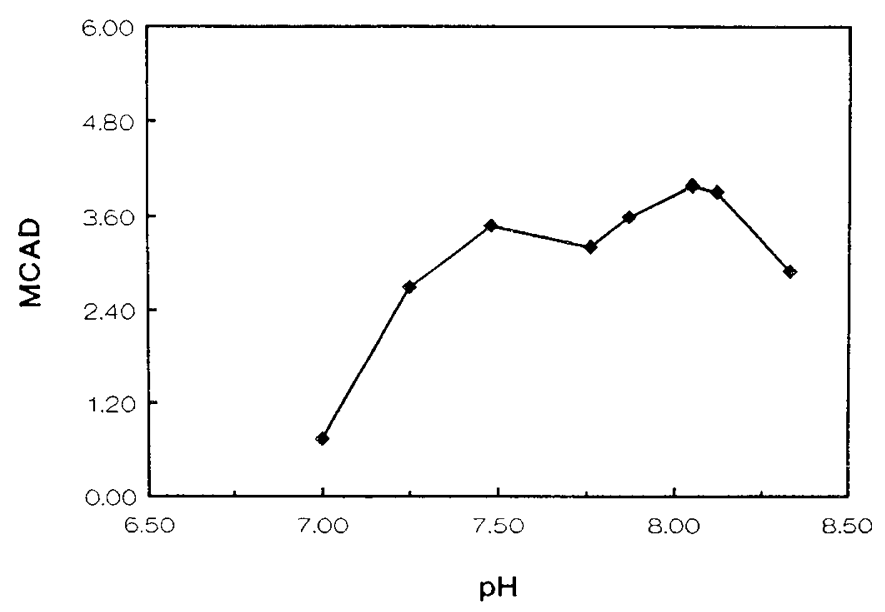

Fig. 1. $\mathrm{pH}$ dependence of the activity of MCAD in lymphocytes of healthy controls. All activities are expressed as $\mathrm{nmol} / \mathrm{mg}$ protein $/ \mathrm{min}$. 
No effect was observed by varying the cysteine concentration. Arbitrarily, it was kept at $0.36 \mathrm{mM}$ in the final reaction mixture. Sufficient crotonase $(0.75 \mathrm{U} /$ assay $)$ was added to convert all octenoyl-CoA (produced by the dehydrogenation reaction) into 3-hydroxyoctanoyl-CoA.

The day-to-day variation of this assay of MCAD was calculated by analyzing a set of mononuclear cells on 4 consecutive days. The lowest and highest values of the enzyme activity were $6 \%$ apart. No attempts were made to study the effect of long-term storage of lymphocytes at $-80^{\circ} \mathrm{C}$ on the enzyme activity, nor was it considered feasible to obtain serial blood samples from a healthy control to assess the intraindividual variation.

Fifteen lymphocyte pellets from healthy adult controls were analyzed. The mean MCAD activity was $3.46 \mathrm{nmol} / \mathrm{min} / \mathrm{mg}$ protein (SD 0.18) (Fig. 2). The lowest and highest values that we observed were 3.12 and $3.68 \mathrm{nmol} / \mathrm{min} / \mathrm{mg}$, respectively. One of the controls had an activity of only $1.92 \mathrm{nmol} / \mathrm{min} / \mathrm{mg}$ protein; this person was subsequently classified as a heterozygote and the value was omitted from Figure 2.

Another 15 subjects were considered obligate heterozygotes because they were the parents of MCAD-deficient patients. Their lymphocyte MCAD activities ranged from $1.15-2.37 \mathrm{nmol} / \mathrm{min} /$ mg protein (mean 1.91; SD 0.41 ). We had the opportunity to test only two siblings of affected patients: one of them was clearly heterozygous and the other one had an activity of $3.03 \mathrm{nmol} /$ $\mathrm{min} / \mathrm{mg}$ and thus fell into the normal range.

Five patients were studied before any riboflavin therapy had been given. In four of them, the activity ranged from $0.08-0.23$ $\mathrm{nmol} / \mathrm{min} / \mathrm{mg}$ protein; the fifth one had an activity of 0.65 . The four with the lower values included the father and his two children, whose histories were published previously (11), as well as the father's sister, who was diagnosed in the course of a large family study. She was in good health and had never had episodes of disturbed energy homeostasis.

Riboflavin was given in amounts of $50-150 \mathrm{mg} / \mathrm{d}$ for a period of 3 wk. Neither the two heterozygotes from different families nor the healthy control subject showed a marked change of MCAD activity. In contrast, all five MCAD-deficient patients at least doubled their lymphocyte enzyme activity after the longterm administration of megadoses of vitamin $B_{2}$. Mean MCAD activity before the start of the therapy was $5.2 \%$ of the mean of the controls; this value increased to $11.8 \% 3 \mathrm{wk}$ later. Even more impressive was the rise in lymphocyte MCAD of the patient originally having $19 \%$ residual activity. Her post- $\mathrm{B}_{2}$ activity of MCAD in lymphocytes was $2.22 \mathrm{nmol} / \mathrm{mg}$ protein/min, a value

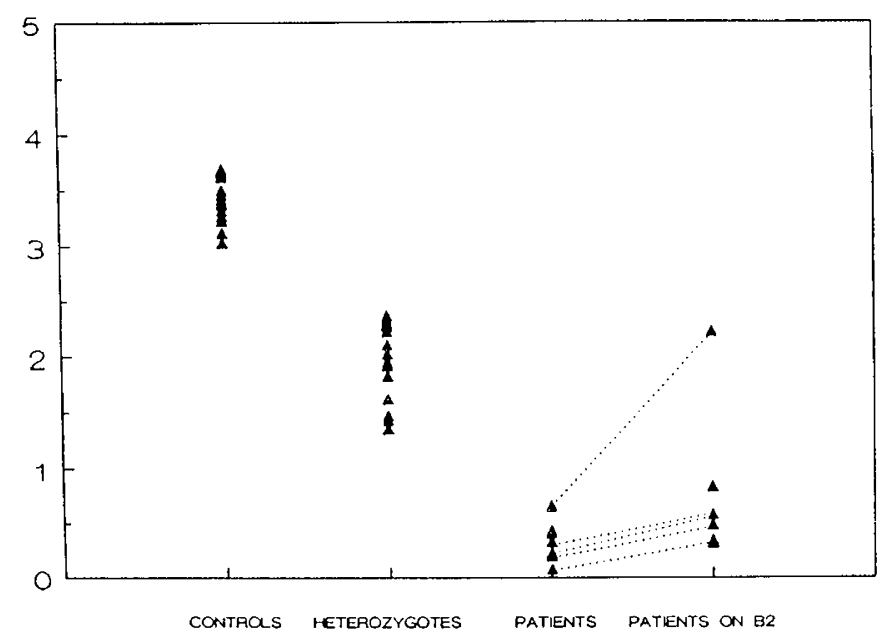

Fig. 2. Activities of MCAD ( $\mathrm{nmol} / \mathrm{mg}$ protein $/ \mathrm{min})$ in lymphocytes of healthy controls $(n=15)$, obligate heterozygotes $(n=15)$, and patients with MCAD deficiency. Patients on $\mathrm{B}_{2}$ received $50-150 \mathrm{mg}$ of riboflavin daily for at least $3 \mathrm{wk}$. No change of activity was observed after administration of this vitamin to two heterozygotes and one control. that is clearly in the heterozygote range. ${ }^{1}$ In the light of this finding, it is advised to refrain from vitamin supplementation in suspected patients when performing the first enzyme test.

In five autopsy liver samples from children who had died of various causes, a mean MCAD activity of $12.4 \mathrm{nmol} / \mathrm{min} / \mathrm{mg}$ protein was observed (range $10.3-14.2 \mathrm{nmol} / \mathrm{min} / \mathrm{mg}$ ). In contrast, the autopsy sample of the patient who had all the biochemical signs of MCAD deficiency such as hypoketotic hypoglycemia and dicarboxylic aciduria showed an activity of $1.97 \mathrm{nmol} / \mathrm{min} /$ mg protein. A biopsy sample from another MCAD-deficient patient had an activity of $0.40 \mathrm{nmol} / \mathrm{min} / \mathrm{mg}$. In all instances, the activities of mitochondrial reference enzymes such as lactate dehydrogenase were taken as criteria for the integrity of the tissue.

\section{DISCUSSION}

The mitochondrial dehydrogenation of fatty acyl-CoA esters is carried out by three different dehydrogenases, each with its own chain-length specificity. Although these specificities are rather broad, the dehydrogenation of octanoyl-CoA will be affected virtually only by MCAD; the contributions of the longchain and the short-chain enzymes are negligible.

The values for MCAD in freshly isolated lymphocytes produced with our gas chromatographic method are in good agreement with those reported earlier for polymorphonuclear leukocytes using the ETF-reduction assay (13). Lymphocytes, however, represent a more homogenous population, and their enzyme activity is therefore expected to be more uniformly distributed. Moreover, the present method does not require the extensive purification of ETF, a relatively labile substance that does not withstand long-term storage. Because PMS is extremely sensitive to light when brought into an aqueous solution, all manipulations had to be carried out in the dark to retain sufficient activity. We used the windowless chromatography room in our laboratory for this purpose. The reaction velocity was linear for at least $30 \mathrm{~min}$, which compares favorably with the $2-5 \mathrm{~min}$ of the ETF-reduction assay.

It has been shown before by Kolvraa et al. (7) that the ${ }^{14} \mathrm{C}$ octanoate degradation assay performed in whole fibroblasts may reveal unacceptably high residual activities in patient cells, a problem that seemed to be overcome by using isolated fibroblast mitochondria (14). Another drawback of this method is its inability to discriminate between heterozygotes and healthy controls (11), which limits its value for genetic investigations.

The method described here is a modification of the technique described by Kolvraa et al. (7). We tested their suggestion to run the assay at pH 7.5 (Fig. 1). Surprisingly, another maximum was found at a $\mathrm{pH}$ value of 8.1 . This may reflect the presence of two different catalytically active forms of the enzyme molecule. Theoretically, one may expect to detect patients who lack either of these forms. Thus far, we have not had the opportunity to test this hypothesis in our collection of patients. A patient with relatively high residual activity would be a candidate for this test.

We have demonstrated that it is possible to establish heterozygosity for MCAD deficiency by this method. The importance of this in the process of genetic counseling should not be underestimated. Although MCAD deficiency appears to be a treatable disease, approximately $25 \%$ of all patients died during an acute crisis. It is therefore our opinion that the number of requests for heterozygote testing will increase, in part because of the high incidence of the disorder.

The effect of riboflavin on lymphocyte MCAD activity in our group of patients is intriguing. Most probably, the high intake of riboflavin leads to an increase of FAD, the cofactor of the enzyme MCAD. It has been shown that a deficiency of riboflavin leads to a profound decrease of the enzyme activity in normal rats (15). Of course, it remains to be verified whether riboflavin

'It has since been shown that the patient with the unusually high residual activity is a compound heterozygote (Gregersen N, unpublished observations). 
therapy has any real in vivo protective effect. We did not have the opportunity to test the effect of this therapeutic regimen on the activity of the hepatic enzyme, nor was it considered justifiable to test the in vivo fatty acid oxidation after riboflavin supplementation by a fasting test.

By the present method, it is relatively easy to detect MCADdeficiency in liver tissue, either in a biopsy or in an autopsy sample. Thus, it is theoretically feasible to investigate all sudden infant death syndrome patients. To our surprise, the activity of liver MCAD in deceased patients was approximately 5-fold higher than in surviving patients. The latter value correlated well with patients' lymphocyte activity $(0.23 \mathrm{nmol} / \mathrm{min} / \mathrm{mg}$ protein after riboflavin). Therefore, it is tempting to conclude that the level of residual enzyme activity alone is not sufficient to predict the clinical outcome. More research is needed to find plausible correlations between the clinical and the biochemical abnormalities.

Acknowledgments. The authors thank Prof. B. J. M. Zegers and Dr. G. T. Rijkers for their help in isolating mononuclear cells; Dr. W. J. Kleijer for his help in culturing fibroblasts; Prof. J. M. Saudubray and Dr. C. Vianey-Liaud for performing ${ }^{14} \mathrm{C}$ octanoate degradation studies in cultured fibroblasts; and $\mathrm{M}$. Hofkamp, A. M. Hemmes, C. Schreuder, R. P. Beekman, and J. $P$. de Jager for referring patients.

\section{REFERENCES}

1. Howat AJ, Bennett MJ, Variend S, Shaw L 1984 Deficiency of medium-chain fatty acyl-CoA dehydrogenase presenting as the sudden infant death syndrome. Br Med J 288:976

2. Didonato S, Gellera C, Rimoldi M, Finocchario G 1988 Mitochondrial diseases due to defects of beta-oxidation. Adv Clin Enzymol 6:24-34

3. Bennett MJ, Coates PM, Hale DE, Millington DS, Pollitt RJ, Rinaldo P, Roe
CR, Tanaka K 1990 Analysis of abnormal urinary metabolites in the newborn period in medium-chain acyl-CoA dehydrogenase deficiency. $J$ Inherited Metab Dis 13:707-715

4. Blakemore AIF, Singleton H, Pollitt RJ, Engel PC, Kolvraa S, Gregersen N, Curtis D 1991 Frequency of the G985 MCAD mutation in the general population. Lancet 337:298-299

5. Frerman FE, Goodman SI 1985 Fluorometric assay of acyl-CoA dehydrogenases in normal and mutant human fibroblasts. Biochem Med 33:38-44

6. Saudubray JM, Coude FX, Demaugre F, Johnson C, Gibson KM, Nyhan WL 1982 Oxidation of fatty acids in cultured fibroblasts: a model system for the detection and study of defects in oxidation. Pediatr Res 16:877-881

7. Kolvraa S, Gregersen N, Christensen E, Holbolth N 1982 In vitro fibroblast studies in a patient with $\mathrm{C}_{6}-\mathrm{C}_{10}$-dicarboxylic aciduria: evidence for a defect in general Acyl-CoA dehydrogenase. Clin Chim Acta 126:53-67

8. Dorland L, Ketting D, Bruinvis L, Duran M 1991 Medium-chain and longchain 3-hydroxymonocarboxylic acids: analysis by gas-chromatography combined with mass spectrometry. Biomed Chromatogr 5:161-164

9. Lowry OH, Rosebrough NJ, Farr AL, Randall RG 1951 Protein measurement with the Folin phenol reagent. J Biol Chem 193:265-275

10. Duran M, Mitchell G, de Klerk JBC, de Jager JP, Hofkamp M, Bruinvis L, Ketting D, Saudubray JM, Wadman SK 1985 Octanoic acidemia and octanoylcarnitine excretion with dicarboxylic aciduria due to a defective oxidation of medium-chain fatty acids. J Pediatr 107:397-402

11. Duran M, Hofkamp M, Rhead WJ, Saudubray JM, Wadman SK 1986 Familial sudden child death and 'healthy' sibs in a family with medium-chain acylCoA dehydrogenase deficiency leading to hypoketotic hypoglycemia and dicarboxylic aciduria. Pediatrics 78:1052-1057

12. Duran $M$, van Vossen R, Bruinvis L, Ketting D, Dorland L, de Klerk JBC 1990 The fate of orally ingested 3-phenylpropionic acid. In Tanaka K, Coates PM (eds) Enzymes of Fatty Acid Oxidation and Their Genetic Defects. Alan R Liss, New York, pp 419-426

13. Coates PM, Hale DE, Stanley CA, Corkey BE, Cortner JA 1985 Genetic deficiency of medium-chain acyl coenzyme A dehydrogenase: studies in cultured skin fibroblasts and peripheral mononuclear leukocytes. Pediatr Res 19:671-676

14. Rhead WJ, Amendt BA, Fritchman KS, Felts SJ 1983 Dicarboxylic aciduria: deficient $\left[\mathrm{I}-{ }^{14} \mathrm{C}\right]$ octanoate oxidation and medium-chain acyl-CoA dehydrogenase in fibroblasts. Science 221:73-75

15. Veitch K, Draye JP, Vamecq J, Causey AG, Bartlett K, Sherratt HSA, van Hoof F 1989 Altered acyl-CoA metabolism in riboflavin deficiency. Biochim Biophys Acta 1006:335-343 